\title{
Patient satisfaction with obstetricians and gynecologists compared with other specialties: analysis of US self-reported survey data
}

This article was published in the following Dove Press journal:

Patient Related Outcome Measures

I3 January 201 I

Number of times this article has been viewed

\author{
Isha Patel $1,2,3$ \\ Jongwha Chang 1,2,3 \\ Jatin Srivastava ${ }^{4}$ \\ Steven Feldman ${ }^{5}$ \\ Michelle Levender ${ }^{5}$ \\ Rajesh Balkrishnan ${ }^{1,2,3,6}$ \\ 'Clinical, Social, and Administrative \\ Sciences, College of Pharmacy, \\ ${ }^{2}$ Center for Medication Use, Policy, \\ and Economics, ${ }^{3}$ Center of Global \\ Health, University of Michigan, Ann \\ Arbor, Michigan; ${ }^{4} \mathrm{EW}$ Scripps School \\ of Journalism, Ohio University, Athens, \\ Ohio; ${ }^{5}$ Department of Dermatology, \\ Wake Forest University Baptist \\ Medical Center, Medical Center \\ Boulevard, Winston-Salem, North \\ Carolina; ${ }^{6}$ Department of Health \\ Management and Policy, University \\ of Michigan, Ann Arbor, Michigan, USA
}

Correspondence: Jongwha Chang Clinical, Social, and Administrative Sciences, College of Pharmacy, 428 Church Street, Room Number 3517, Ann Arbor, MI 48I04, USA

Tel +l 734936 I505

Fax $+|734615817|$

Email jochang@umich.edu
Background: Few studies in the US have evaluated patient satisfaction with physicians across different specialties. We examined patient satisfaction and attitudes toward physicians during outpatient visits in the health care system, including obstetricians and gynecologists and other specialty physicians.

Methods: We conducted a cross-sectional and national Web-based survey among anonymous patients who rated their physicians according to satisfaction with treatment on the basis of their experience during their most recent outpatient visits. The survey was user-friendly, validated, and helped patients identify their physicians according to specialty and rate them on a scale of 0 ("not at all satisfied") to 10 ("extremely satisfied"). The patient satisfaction in obstetricians and gynecologists and other specialists were assessed using logistic regression analysis.

Results: A total of 7938 patients who rated physicians belonging to the categories of obstetricians and gynecologists $(n=1903)$ and other specialties $(n=6035)$ were included in the study. Other things being equal, the odds of earning a satisfaction rating were almost 55\% higher for visits to obstetricians and gynecologists than for other specialties (odds ratio [OR] 1.55 [1.15, 2.09], $P<0.01)$. Also, other things being equal, compared with other specialists, the odds of patient satisfaction due to the caring and friendly attitude of a physician were three times higher for obstetricians and gynecologists, with a logit coefficient of 1.28 (OR, 3.59 [3.17, 4.07], $P<0.001)$.

Conclusion: Patient satisfaction ratings associated with caring and friendly attitude were higher for obstetricians and gynecologists compared to other specialists. Even though several factors influence patient satisfaction, adoption of factors like reducing waiting times, effective patient-physician communication, and involving patients in the decision-making process might aid physicians in achieving optimal results.

Keywords: patient satisfaction, attitudes, specially physicians

\section{Introduction}

Patient satisfaction is gaining increasing attention because of data showing this to be a critical factor in health outcomes. Patients who report higher satisfaction with their care and greater trust in their health care provider are more adherent to treatment and therefore have better treatment outcomes. ${ }^{1}$ Patient satisfaction has far-reaching effects. There is a direct correlation between malpractice lawsuits and low patient satisfaction scores. ${ }^{2}$ Obstetrics may carry the highest risk of malpractice suits, which has likely contributed to the decreasing percentage of obstetrics and gynecology residency slots filled by US medical graduates, from $88.3 \%$ to $76.3 \%$ in $1999-2000 .^{3}$ This problem can be addressed by an improved understanding of the factors contributing to patient satisfaction. 
Defining patient satisfaction as a construct is a complex task that involves numerous factors. ${ }^{4}$ Assessment of physician performance and overall quality of care is determined by both objective features (eg, accessibility of services, medical expertise, and continuity of care) and more subjective features (eg, perception of pain, perception of how caring a provider is, and how effectively he or she communicates with a given patient). In obstetrics, the indisputable primary objective of care is the overall health of mother and baby. In addition, there exist many more subjective factors that influence a woman's overall satisfaction with her obstetric care..$^{5-7}$ Murray et al outlined a number of such factors affecting a woman's satisfaction with her birthing experience, which include the woman being conscious and in control of her body during the birthing process, participation in the decision-making process, presence of a support person during childbirth, supply of information concerning childbirth and nursing a child, nursing support, length of stay in hospital, and the physical environment in which the birth and labor take place. ${ }^{8,9}$ Gender of the obstetrician has been shown to influence patient satisfaction as well. One study examining this issue looked at physician-patient communication during an initial prenatal visit. They found that male obstetricians conducted lengthier visits, shared information in a way that was rated as being better understood, were perceived as showing more concern, and were perceived as providing more direction and orientation when compared with female obstetricians. Female obstetricians, on the other hand, were found to engage in more affective communications, including agreements, disagreements, and laughter, and were perceived as demonstrating enhanced emotional responsiveness and a better informational partnership relative to their male counterparts. ${ }^{10}$

Empathy is a critical aspect of physician-patient communication. Generally, obstetricians and gynecologists rank higher for empathy compared with specialists in radiology, neurosurgery, orthopedic surgery, and anesthesiology. ${ }^{11}$ Differences in empathy between specialties may stem from people with different degrees of interpersonal skills being attracted to different specialties. ${ }^{11}$ A study conducted in Sweden showed higher patient satisfaction and overall better health status with gynecology compared with surgery, orthopedics, internal medicine, and psychiatry. ${ }^{12}$ Such differences in personality traits and interpersonal skills that attract providers to particular specialties may contribute to differences in patient satisfaction patterns between obstetricians and gynecologists and other medical specialties.

In this study, we attempted to characterize patient satisfaction with ambulatory care in obstetrics and gynecology. Although other studies have explored this area, most have focused on inpatient satisfaction. Differences in the setting of care, eg, inpatient versus outpatient, may significantly affect the factors involved in patient satisfaction. Factors like hospital size, teaching status of the hospital, hospital environment, patient autonomy, and privacy, have been studied extensively in inpatient settings but not in outpatient settings. Research has shown that patient satisfaction is significantly decreased in large hospitals, teaching hospitals, hospitals with restrictive autonomy and privacy, and hospitals without efficient teamwork. ${ }^{13-15}$ On the other hand, satisfaction related to health status is significantly associated with inpatient care because it has greater short-term costs, provides more intensive interventions with maximum control of environment, and is one of the more desirable choices for women with serious birth complications. However, behaviors established with inpatient care are less likely to be maintained post-treatment as opposed to outpatient care. ${ }^{16}$ Therefore, results from inpatient satisfaction studies may not be generalizable to outpatient satisfaction. We examine various factors that may influence a woman's overall satisfaction with her obstetrician and gynecologist during office visits.

\section{Methods}

Data on patient satisfaction with US obstetricians and gynecologists were obtained using a validated Web-based convenience sample (www.DrScore.com, Medical Quality Enhancement Corporation, Winston-Salem, NC, USA). ${ }^{17-19}$ This anonymous survey is promoted primarily through online search engines. ${ }^{20}$

From April 2005 to May 2008, survey data on a convenience sample of 40,510 patients were collected. We examined surveys regarding visits to obstetricians and gynecologists and excluded data on all primary practitioners, which resulted in a sample of 20,888. Incomplete surveys were excluded if more than three items relating to physician satisfaction score were incomplete. Missing items were imputed by using the means of the nonmissing items. This resulted in 7938 surveys being included in the data analysis.

For their most recent visit to a physician, patients were asked to rate their satisfaction with the visit on a scale of 0 ("not at all satisfied") to 10 ("extremely satisfied"). A "not applicable" option was also available. A patient satisfaction score was computed for "physician care" based on nine items evaluating the thoroughness of care, physician communication, follow-up, listening, demeanor, discussion of test results, answering questions, treatment success, and inclusion of the patient in the decision-making process. The score obtained from the physician satisfaction scale was added and ranged from 0 to 100 by taking the mean of each item and 
multiplying it by 10 , representing complete satisfaction on the characteristics assessed.

Patients were asked to report their waiting time and time spent with the physician. Personal information, race, and severity of illness data were not collected. Institutional Review Board approval was obtained prior to data analysis. ${ }^{17,18}$ The survey questions have a reliability of 0.95 and a validity of 0.99 , as established and described in other studies. ${ }^{21}$

\section{Sample}

A Pearson's Chi-squared test was performed to test the significance between mean patient satisfaction score across obstetricians and gynecologists and other specialists in the initial descriptive statistical analysis. It was also performed to test the bivariate association between patient satisfaction and waiting time, as well as patient satisfaction and spending time with obstetricians and gynecologists and other specialists. The predictor variables included were physician specialty, the caring and friendly attitude of the physician, patient age, first visit, waiting time to see the physician, and time spent with the physician. Logistic regression analysis was conducted to predict patient satisfaction with the physician and with the visit for the different categories of health care providers. All variables except age, waiting time, and time spent with the physician were coded as follows: specialty $(0=$ other specialties, $1=$ obstetrics and gynecology) and first visit ( $0=$ yes,

$1=$ no). Waiting time and time of visit were continuous variables. The age variable was coded as follows: $(0=$ under 18 years, $1=18-24$ years, $2=25-34$ years, $3=35-44$ years, $4=45-64$ years, and $5=$ over 65 years). The significance level was set at 0.05 for all the analyses. All statistical analysis was carried out using Stata statistical software, version 10 (StataCorp, College Station, TX, USA).

\section{Results}

The study sample comprised 1903 obstetricians and gynecologists and 6035 other specialists (Table 1). On a scale of $0-100$, the mean satisfaction with physician score was $65.1(P<0.001)$ for obstetricians and gynecologists and $58.1(P<0.001)$ for other specialists. On a scale of $0-10$, patient satisfaction due to the physician's caring and friendly attitude was $6.65(P<0.001)$ for obstetricians and gynecologists and $5.86(P<0.001)$ for other specialists. There were more surveys completed for return obstetrician and gynecology visits $(87.4 \%)$ than for the initial visit (12.6\%). Patients aged 18-34 years comprised the majority of survey respondents for obstetrician and gynecology visits $(69.0 \%)$. For visits to specialists other than obstetricians

Table I Descriptive characteristics in the study population for assessing patient satisfaction seen with obstetricians and gynecologists and other specialists $(n=7938)$

\begin{tabular}{|c|c|c|c|}
\hline $\begin{array}{l}\text { Baseline } \\
\text { characteristics }\end{array}$ & $\begin{array}{l}\text { Obstetricians and gynecologists } \\
(n=1903)(\text { mean (SD)) }\end{array}$ & $\begin{array}{l}\text { Other specialists } \\
(n=6035)(\text { mean }(S D))\end{array}$ & $\begin{array}{l}\text { Total }(n=7938) \\
(\text { mean }(S D))\end{array}$ \\
\hline $\begin{array}{l}\text { Patient satisfaction score* } \\
(0-100)\end{array}$ & $65.90(40.29)$ & $58.05(41.06)$ & $59.93(41.01)$ \\
\hline $\begin{array}{l}\text { Caring and friendly attitude* } \\
(0-10)\end{array}$ & $6.65(4.18)$ & $5.86(4.29)$ & $6.05(4.27)$ \\
\hline Age (years) & $25.34(9.58)$ & 33.77 (II.27) & 31.75 ( 11.47$)$ \\
\hline$<18$ & $11.99 \%$ & $5.56 \%$ & \\
\hline $18-24$ & $42.18 \%$ & $17.69 \%$ & \\
\hline $25-34$ & $27.80 \%$ & $25.17 \%$ & \\
\hline $35-44$ & $16.71 \%$ & $39.03 \%$ & \\
\hline $45-64$ & $1.06 \%$ & $10.09 \%$ & \\
\hline$>65$ & $0.27 \%$ & $2.46 \%$ & \\
\hline First visit* & |2.6| (33.20) & $22.15(41.53)$ & $19.86(39.90)$ \\
\hline Yes & $12.61 \%$ & $22.15 \%$ & \\
\hline No & $87.39 \%$ & $77.85 \%$ & \\
\hline Waiting time (minutes)* & $26.85(21.66)$ & $29.07(23.36)$ & $28.54(22.98)$ \\
\hline$<15$ & $35.84 \%$ & $34.75 \%$ & \\
\hline $15-30$ & $36.00 \%$ & $32.28 \%$ & \\
\hline $30-60$ & $16.55 \%$ & $17.93 \%$ & \\
\hline$>60$ & $11.61 \%$ & $15.05 \%$ & \\
\hline Spending time (minutes)* & $9.48(3.96)$ & $8.80(4.19)$ & $8.96(4.15)$ \\
\hline$<5$ & $17.81 \%$ & $23.05 \%$ & \\
\hline $5-10$ & $23.75 \%$ & $26.45 \%$ & \\
\hline$>10$ & $58.43 \%$ & $50.51 \%$ & \\
\hline
\end{tabular}

Notes: Pearson's Chi-squared test comparing means for obstetricians and gynecologists with other specialists was performed. $* P$ value $<0.00 I$. Abbreviation: SD, standard deviation. 
and gynecologists, the majority of survey respondents were aged 35 years and older (51.6\%). Overall, patients waited a significantly shorter time for obstetrician and gynecologist visits (average 26.8 minutes) compared with other specialists (29.1 minutes, $P<0.001$ ) Patients reported spending an average of 9.5 minutes with their obstetrician and gynecologist compared with 8.8 minutes with other specialists; this difference was statistically significant $(P<0.001)$.

In order to deal with the dichotomous dependent variable of patient satisfaction score, a logistic regression analysis model was used. Six independent variables were used to predict patient satisfaction score, including specialty, caring and friendly attitude of the physician, age, first visit, waiting time, and time spent with the physician.

Controlling for all the potential confounding variables, the odds of being satisfied were almost $55 \%$ higher for visits to obstetricians and gynecologists than for other specialties (OR 1.55 [1.15, 2.09], Table 2). Also, compared with other specialists, the odds of patient satisfaction due to the caring and friendly attitude of the physician were 3.5 times greater for obstetricians and gynecologists, with a logit coefficient of 1.28 (OR 3.59 [3.17, 4.07], Table 2). Patients aged 18-24 years were the least likely to be satisfied. After controlling for the confounding variables, compared with other specialists, the odds of being satisfied with obstetricians and gynecologists were 58\% higher in patient aged $18-24$ years, $72 \%$ higher in patients aged 35-44 years, almost 2.6 times higher in patients aged 45-64 years, and almost 3.1 times higher in patients aged over 65 years (Table 2). The OR for waiting time was

Table 2 Logistic regression analysis of patient satisfaction with obstetricians and gynecologists and other specialists $(n=7938)$

\begin{tabular}{lllll}
\hline Variable & \multicolumn{3}{l}{ Patient satisfaction score } & \\
\cline { 2 - 5 } & $\begin{array}{l}\text { Coefficient } \\
\text { of variation }\end{array}$ & OR & Significance & $\mathbf{9 5 \% ~ C l ~}$ \\
\hline $\begin{array}{l}\text { Obstetricians and } \\
\text { gynecologists }\end{array}$ & 0.44 & 1.55 & $* *$ & {$[1.15,2.09]$} \\
$\begin{array}{l}\text { Caring and } \\
\text { friendly attitude }\end{array}$ & 1.28 & 3.59 & $* * *$ & {$[3.17,4.07]$} \\
Age (years) & & & & \\
18-24 & 0.46 & 1.58 & $*$ & {$[1.01,2.47]$} \\
$25-34$ & 0.33 & 1.39 & & {$[0.89,2.18]$} \\
$35-44$ & 0.54 & 1.72 & $*$ & {$[1.11,2.66]$} \\
$45-64$ & 0.95 & 2.60 & $* *$ & {$[1.41,4.77]$} \\
$65+$ & 1.13 & 3.10 & $* *$ & {$[1.47,6.51]$} \\
First visit & 0.22 & 1.24 & & {$[0.86,1.81]$} \\
Waiting time & -0.04 & 0.95 & $* *$ & {$[0.95,0.96]$} \\
Length of visit & 0.02 & 1.02 & & {$[0.98,1.06]$} \\
Constant & -2.02 & & & \\
\hline
\end{tabular}

Notes: $* P<0.05$; **P $<0.01$; $* * * P<0.001$.

Abbreviations: $\mathrm{Cl}$, confidence interval; $\mathrm{OR}$, odds ratio.
0.95 , indicating that the odds of being satisfied decreases by $5 \%$ with additional waiting time in the clinic in order to meet the physician, as shown in Table 2.

Time spent with the physician had a significant effect on satisfaction score. Scores averaged 17.2 for obstetrician and gynecology visits reported as lasting less than 5 minutes, 44.6 for visits lasting 5-10 minutes, and 88.2 for visits lasting more than 10 minutes (Figure 1). This effect was also seen for visits to other specialists. Satisfaction scores averaged 17.7 for visits lasting less than 5 minutes, 40.4 for visits lasting 5-10 minutes, and 83.2 for visits lasting more than 10 minutes (Figure 1). In both groups, visits lasting 5-10 minutes and more than 10 minutes resulted in statistically significant differences in average scores $(P<0.05)$.

There was a strong inverse relationship between waiting time and satisfaction scores for obstetrician and gynecology as well as other specialty visits. For a waiting time of less than 15 minutes, the average score was 88.69 for obstetrician and gynecology visits and 82.83 for other specialty visits. For waiting times of 15-45 minutes, the average score was 66.52 for obstetrician and gynecology visits and 59.57 for other specialty visits; for waiting times of 45-60 minutes, the average score was 43.48 for obstetrician and gynecology visits and 39.43 for other specialty visits; for waiting times of greater than 60 minutes, the average score was 30.19 for obstetrician and gynecology visits and 25.72 for other specialty visits (Figure 2). Differences between groups, by waiting time, were all found to be significant $(P<0.05)$.

\section{Discussion}

Few studies have reported on patient satisfaction with outpatient visits comparing obstetricians and gynecologists with other specialists. We found that patient satisfaction

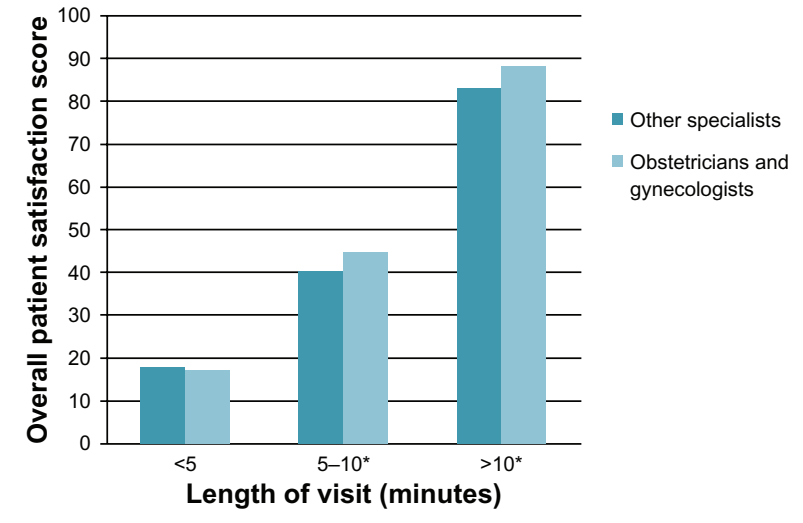

Figure I Relationship between patient satisfaction and spending time as a function of physician specialty.

Notes: Pearson's Chi-squared test comparing means of length of visits to obstetricians and gynecologists with other specialists was performed. $* P$ value $<0.05$. 


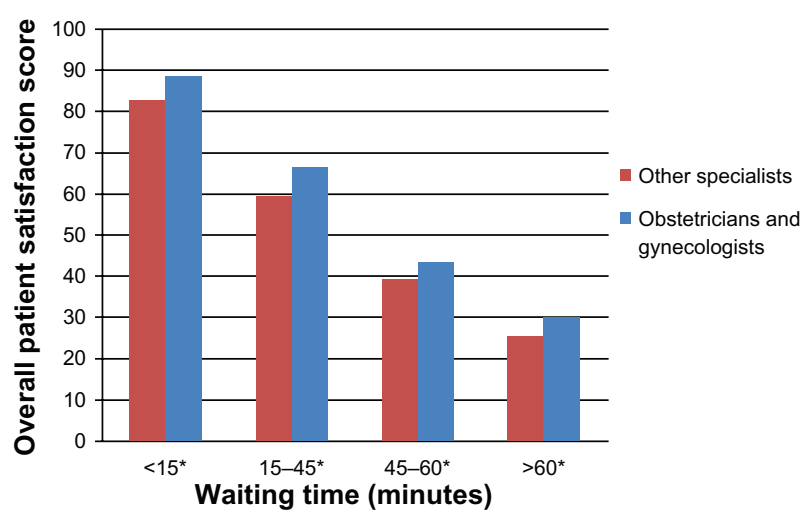

Figure 2 Relationship between patient satisfaction and waiting time as a function of physician specialty.

Notes: Pearson's Chi-squared test comparing means of waiting times for obstetricians and gynecologists with other specialists was performed. $* P$ value $<0.05$.

scores were significantly higher for visits to obstetricians and gynecologists than for other specialties. This is interesting considering that lower patient satisfaction scores tend to correlate with higher likelihood of a lawsuit, ${ }^{2}$ and obstetricians and gynecologists are among the most common specialties to be sued for malpractice. Because of the intimate nature of obstetrician and gynecology care and the critical role these physicians play in some of the most memorable times in women's lives, particularly in caring for them during pregnancy and childbirth, patients are more likely to develop closer and more personal relationships with their obstetricians and gynecologists. Perhaps the stakes are higher for patients when it comes to obstetric issues; thus, when expectations are not met or outcomes are poor, any dissatisfaction is greater, resulting in a higher incidence of malpractice suits. However, in our study, patients were very satisfied with their obstetricians and gynecologists relative to other specialists. As expected, the caring and friendly nature of the health care provider and patient waiting times were both significant predictors of patient satisfaction. Consistent with the results of previous studies, longer waiting times were associated with low patient satisfaction scores. Conversely, the caring and friendly nature of the health care provider was positively associated with patient satisfaction..$^{18,22-24}$

Although the study has important implications for health care professionals and policy makers, it has several limitations. Its cross-sectional nature does not permit causal inferences. Also, because the data were obtained from a Web-based survey, there may be sample bias by having selectively attracted respondents who were experienced using the Internet. Similarly, patients who had strong feelings about their doctor, whether positive or negative, were likely to be more inclined to take the time to complete the survey in comparison with patients who may have been more neutral. Although this may have resulted in more exaggerated results, the relative relationships revealed should still be valid. The data were based solely on self-report. Therefore, it is possible that recall bias is present such that overall satisfaction influenced the perception of other variables. The imputation used for handling missing data in this study has certain limitations as well. Even though imputation creates a complete dataset and makes data analysis consistent, and because data presentation is simpler, it may distort the association between certain key variables. Also, imputation may lead to data fabrication to a certain degree, which may overestimate the precision of the survey estimates. ${ }^{25}$ Personal factors, including race, health status, type of insurance, and patient trust in the physician, were not recorded. This might affect the generalizability of the study results to the wider population. Also, variables influencing patient satisfaction, such as accessibility, level of physician communication, clarity, and patient expectations of the visit, were not recorded, although such data may have offered additional insights.

This study has important implications for health care professionals. It presents strong evidence that patients are happier with their obstetricians and gynecologists than with other specialties. Patient satisfaction is an important factor in adherence to treatment, which is essential to achieving good outcomes. Thus, efforts should be made to maximize patient satisfaction. Minimizing wait time, providing efficient and flexible appointment scheduling with the help of electronic technology, communicating effectively with patients by projecting friendliness, openness, calmness, and attentiveness while listening to the patient, providing reassurance, involving the partner of the patient, and increasing the duration of the patient encounter are some ways to improve patient satisfaction. ${ }^{26-28}$ In fact, rather than actually increasing time spent with patients, physicians need only to increase the perceived time spent, which can be accomplished with simple changes in body language. For example, sitting down during an encounter causes patients to perceive a visit as lasting longer. ${ }^{29}$ This study has implications for health care policy makers as well. Research has shown that a patientcentered focus is also one of the strategies to achieving cost-effective quality of care. ${ }^{30}$ Pay for performance has been shown to have an impact on patient satisfaction by enhancing physician knowledge, increasing awareness of guidelines, encouraging prevention and follow-up, reducing errors and costs, ensuring a uniform level of care, and motivating physicians to deliver better care. It may also be argued that steps toward increasing patient satisfaction may, in some cases, facilitate effective implementation of a pay 
for performance concept. From this perspective, variables with significant associations with patient satisfaction in this study may be viewed as stepping stones toward successful implementation of a pay for performance concept. ${ }^{31}$

\section{Conclusion}

Patient satisfaction is an important component of health care delivery. Patient satisfaction is multifactorial and has farreaching effects, so more research is needed to understand it better, allowing for identification and implementation of additional strategies promoting patient centeredness and pay for performance in order to improve it.

\section{Disclosure}

IP, JC, JS, ML, and RB have no conflicts of interest to declare in this work. SF has equity in the Medical Quality Enhancement Corporation, which developed the DrScore. com website. This study was not funded by any source.

\section{References}

1. Felkey BG. Adherence screening and monitoring. Am Pharm. 1995; NS35:42-51.

2. Stelfox HT, Gandhi TK, Orav EJ, Gustafson ML. The relation of patient satisfaction with complaints against physicians and malpractice lawsuits. Am J Med. 2005;118:1126-1133.

3. Brotherton SE, Rockey PH, Etzel SI. US graduate medical education, 2003-2004. JAMA. 2004;292:1032-1037.

4. Anderson R, Barbara A, Feldman SR. What patients want: A content analysis of key qualities that influence patient satisfaction. J Med Pract Manage. 2007;22:255-261.

5. Tarantino D. How should we measure patient satisfaction? Physician Exec. 2004;30:60-61.

6. Heje HN, Vedsted P, Sokolowski I, Olsen F. Doctor and practice characteristics associated with differences in patient evaluations of general practice. BMC Health Serv Res. 2007;7:46.

7. Hodnett ED. Pain and women's satisfaction with the experience of childbirth: A systematic review. Am J Obstet Gynecol. 2002;186: S160-S172.

8. Murray I, Wilcock A, Kobayashi L. Obstetrical patient satisfaction. $J$ Health Care Mark. 1996;3:54-57.

9. Wilcock A, Kobayashi L, Murray I. Twenty-five years of obstetric patient satisfaction in North America: A review of the literature. J Perinat Neonatal Nurs. 1997;10:36-47.

10. Roter DL, Geller G, Bernhardt BA, Larson SM, Doksum T. Effects of obstetrician gender on communication and patient satisfaction. Obstet Gynecol. 1999;5 Pt 1:635-641.

11. Hojat M, Gonnella JS, Nasca TJ, Mangione S, Vergare M, Magee M. Physician empathy: Definition, components, measurement, and relationship to gender and specialty. Am J Psychiatry. 2002;159:1563-1569.

Patient Related Outcome Measures

\section{Publish your work in this journal}

Patient Related Outcome Measures is an international, peer-reviewed, open access journal focusing on treatment outcomes specifically relevant to patients. All aspects of patient care are addressed within the journal and practitioners from all disciplines are invited to submit their work as well as healthcare researchers and patient support groups. Areas covered will Submit your manuscript here: http://www.dovepress.com/patient-related-outcome-measures-journal
12. Rahmqvist M. Patient satisfaction in relation to age, health status and other background factors: A model for comparisons of care units. Int J Qual Health Care. 2001;13:385-390.

13. Corrigan PW. Consumer satisfaction with institutional and community care. Community Ment Health J. 1990;26:151-165.

14. Young GJ, Meterko M, Desai KR. Patient satisfaction with hospital care: Effects of demographic and institutional characteristics. Med Care. 2000;38:325-334.

15. Barr DA. Race/ethnicity and patient satisfaction. Using the appropriate method to test for perceived differences in care. J Gen Intern Med. 2004; 19:937-943.

16. Williams AC, Richardson PH, Nicholas MK, et al. Inpatient vs outpatient pain management: Results of a randomised controlled trial. Pain. 1995;66:13-22.

17. Kong MC, Camacho FC, Feldman SR, Anderson RT, Balkrishnan R. Correlates of patient satisfaction with physician visit: Differences between elderly and non-elderly survey respondents. Health Qual Life Outcomes. 2007;5:62.

18. Anderson RT, Camacho FC, Balkrishnan R. Willing to wait? The influence of patient wait time on satisfaction with primary care. BMC Health Serv Res. 2007;7:31.

19. DrScore. Available from: http://www.drscore.com. Accessed on Dec 6 2010.

20. The people's pharmacy. Available from: http://www.peoplespharmacy. com/index.asp. Accessed Dec 62010.

21. Camacho FT, Feldman SR, Balkrishnan R, Kong MC, Anderson RT. Validation and reliability of 2 specialty care satisfaction scales. $\mathrm{Am} J$ Med Qual. 2009;24:12-18.

22. Jackson JL, Chamberlin J, Kroenke K. Predictors of patient satisfaction. Soc Sci Med. 2001;52:609-620.

23. Dubina MI, O'Neill JL, Feldman SR. Effect of patient satisfaction on outcomes of care. Expert Rev Pharmacoecon Outcomes Res. 2009;9:393-395.

24. Uhas AA, Camacho FT, Feldman SR, Balkrishnan R. The relationship between physician friendliness and caring, and patient satisfaction: Findings from an Internet-based survey. The Patient: Patient-Centered Outcomes Research. 2008;6:91-96.

25. Brick JM, Kalton G. Handling missing data in survey research. Stat Methods Med Res. 1996;5:215-238.

26. Buller MK, Buller DB. Physicians' communication style and patient satisfaction. J Health Soc Behav. 1987;28:375-388.

27. Proctor S, Wright G. Consumer responses to health care: Women and maternity services. Int J Health Care Qual Assur Inc Leadersh Health Serv. 1998;11:147-155.

28. DeFrancesco MS. Practice smarter ... not harder! Obstet Gynecol. 2008; 112:10-13.

29. Baldwin HE. Tricks for improving compliance with acne therapy. Dermatol Ther. 2006;19:224-226.

30. DiGioia A 3rd, Lorenz H, Greenhouse PK, Bertoty DA, Rocks SD. A patient-centered model to improve metrics without cost increase: Viewing all care through the eyes of patients and families. J Nurs Adm. 2010;40:540-546.

31. Augustine S, Lawrence RH, Raghavendra P, Watts B. Benefits and costs of pay for performance as perceived by residents: A qualitative study. Acad Med. 2010;85:1888-1896.

include: Quality of life scores; Patient satisfaction audits; Treatment outcomes that focus on the patient; Research into improving patient outcomes; Hypotheses of interventions to improve outcomes; Short communications that illustrate improved outcomes; Case reports or series that show an improved patient experience; Patient journey descriptions or research. 